\title{
FACTORS INFLUENCING THE FEE FOR USE OF THE RAILWAY INFRASTRUCTURE
}

\author{
Petr Novák*, VÁClav Cempírek \\ Jan Perner Transport Faculty, Studentská 95, Pardubice, Czech Republic \\ * corresponding author: petr.novak2@student.upce.cz
}

\begin{abstract}
It is necessary to update the current system of levying charges for railway infrastructure to reflect the current market situation, to take into account the new transport strategy established by the European Union, and to reflect legislative changes in relation to Directive 2012/34/EU on creating a single European railway area. International trends aim to categorize tracks according to technical parameters and parameters based on shipment time, as well as many others. The existence of different opinions on the amount and way to charge fees for railway infrastructure have led the authors of this academic paper to create a plan for a system of charges to be derived from the current production factors as well as from a number of specific new factors used in countries neighboring the Czech Republic.
\end{abstract}

KEYWORDS: prices, product factors, specific factors, transport routes, carriers.

\section{INTRODUCTION}

As defined in the White Paper, "Roadmap to a Single European Transport Area - Towards a competitive and resource efficient transport system," EU transport policy currently describes the point in time when the transport system's users will cover all the costs they create. These costs include infrastructure costs (the development and maintenance of transport routes) as well as external ones - emphasized in the principle of "the user/polluter pays," which influences the environment and growing congestion.

At the same time, the European Commission (EC) has set requirements for lowering greenhouse gas emissions to around $20 \%$ of the 2008 level by 2030 and $60 \%$ of the 1990 level by 2050 . These results should be attained by shifting $30 \%$ of road transport to railways by the year 2030 and up to $50 \%$ of such transport by 2050.

The Czech Republic's (CR) priority in transport policy, in accordance with Directive 2012/34/EU of the European Parliament and of the Council of 21 November 2012 on creating a single European railway area, is implementing a competitive railway system and thereby equalizing conditions on the transport market.

The extensive railway network in the $\mathrm{CR}$ is in direct contrast with the actuality of its fully operational lines, on which high-speed, passenger, and freight trains run and which are able to compete with road transport at roughly one fifth the rate. According to the Pareto principle, $20 \%$ of the causes create $80 \%$ of the effects, which applies here in an exemplary way: the majority of railway system tracks have economic problems, because the revenues from transport do not cover the costs.

\section{The Current State of Charging For RAILWAY INFRASTRUCTURE IN THE CR}

The amount to be charged is dependent on the distance traveled and the gross weight of the train, which the carrier reports to the infrastructure operator. These two parameters take into account the costs for transporting the train along the appropriate line (train-km - train kilometers) and determine the wear on the transport infrastructure caused by the train's passage (GTK - gross ton-kilometer).

Charging for railway infrastructure is divided into two components. The first component used for charging is the actual use of the railway infrastructure; the second component is the fee for allocating capacity.

\subsection{Charging For Railway INFRASTRUCTURE USE IN THE CR}

The Network Statement and the Ministry of Finance's current Price Bulletin provide annual updates on the prices for train passage on the nationwide and regional lines of the domestic railway infrastructure operated by the Railway Infrastructure Administration (RIA) in addition to the conditions for their use.

These prices include not only the individual journey of a train along a track but also the organization of track-based modes of transportation, telecommunication connections between the railway operator's employees and the train's staff, publishing regulations, and transmitting information to carriers.

The basic price is the price calculated according to a costing model using the unit prices set for passenger trains or freight trains. The basic price calculation has been set as the distance traveled by a given train along a category of track (LE, LC, or LR) using data on the length and category of the sections (borders). 
For calculating prices, the actual route covered by the train is decisive except in cases when the train is rerouted on account of a traffic disruption. The basic price is calculated according to Equations 1, 2, and 3 below.

$$
C_{z}=C_{1}+C_{2}[C Z K]
$$

where:

- $C_{z}$ is the overall basic price for using railway infrastructure for the train's journey [CZK],

- $C_{1}$ is the price for using railway infrastructure for the train's journey in the area of performance measured by the train kilometers traveled [CZK], and

- $C_{2}$ is the price for using railway infrastructure for the train's journey in the area of performance measured by the gross train kilometers traveled.

$$
C_{1}=S_{1 E} * L_{E}+S_{1 C} * L_{C}+S_{1 R} * L_{R}[C Z K]
$$

where:

- $S_{1}$ is the price for $1 \mathrm{~km}$ of a train journey (train-km) along E, C, or R category tracks [CZK * $\mathrm{km}^{-1}$ ] and

- $L_{E}, L_{C}$, and $L_{R}$ are the distances traveled by a train along $E, C$, or $R$ category tracks [km].

$C_{2}=S_{2 E} * Q * L_{E}+S_{2 C} * Q * L_{C}+S_{2 R} * Q * L_{R}[C Z K]$

where:

- $S_{2}$ is the price per 1000 gross ton kilometers transported along $E, C$, or $R$ category tracks $\left[\mathrm{CZK}^{*} \mathrm{GTK}^{-1}\right]$,

- $Q$ is one thousandth of the gross weight of the train in tons. The train's weight is the sum of the weight of all the train cars including the weight of the passengers or freight [thousandths of gross tons], and

- $L_{E}, L_{C}$, and $L_{R}$ are the distances traveled by a train along $E, C$, or $R$ category tracks [km].

The price $C_{2}$ is calculated separately for each section of track traveled by the given train after a change in its weight (adding/subtracting train cars, a change in the type of train from a passenger train to a train with a trainset or the reverse).

\subsection{ChARGES FOR CAPACITY ALLOCATION}

This fee is established in conjunction with:

- the length of the time interval between when the request for railway infrastructure capacity allocation was submitted and the day that has been requested for its use,

- the relationship between the submitted request for railway infrastructure capacity allocation and the deadline for composing the annual railway timetable (RT) or changes planned to the timetable, and
- the difficulty of processing the request.

Included in the charge for allocating railway infrastructure capacity is thus compensation for the process of allocating line capacity, compensation for processing the timetable for the train assigned to the given carrier request (except for printing costs and distribution aids), compensation for the train's operative deployment, and a fee for negotiating and executing the request on short notice.

The price for allocating railway infrastructure capacity is calculated according to the equation:

$$
C_{P K}=K_{1}+K_{2} * L+K_{3} * d[C Z K]
$$

where:

- $C_{P K}$ is the price for allocating transport infrastructure $[\mathrm{CZK}]$,

- $K_{1}$ is the rate for processing and determining the RT and allocating transport infrastructure [CZK],

- $K_{2}$ is the rate for the construction of the train route $\left[\mathrm{CZK}^{*} \mathrm{~km}^{-1}\right]$,

- $L$ is the distance of the allocated route between the starting and ending point of the track on the railway network, where the RIA fills the role of the line operator or allocator of capacity $[\mathrm{km}]$,

- $K_{3}$ is the daily rate for train route allocation $\left[\mathrm{CZK}^{*}\right.$ day $\left.^{-1}\right]$, and

- $d$ is the number of days of the journey for which the respective route has been allocated [days].

\section{International Charges for RAILWAY INFRASTRUCTURE}

In all countries, the basic system for determining railway infrastructure prices is founded on a similar basis, i.e., according to train kilometers, gross ton kilometers, or using both these transport functions on a specific track. In specific countries, other parameters that modify the final price for using railway infrastructure have also been established. These often have decisive influence on the choice of transport, and it is in the interest of each infrastructure manager to be flexible when adjusting the charges for railway infrastructure use.

Using an extensive analysis of the fundamentals and procedures for calculating prices for using railway infrastructure employed by infrastructure managers who proceed in accordance with Directive 2012/34/EU, the authors have formed the opinion that it is necessary to supplement the current method for calculating prices with a number of specific factors.

\subsection{Consolidating THE PRICES FOR PASSENGER AND FREIGHT TRANSPORT}

The motivation for consolidating the basic prices for passenger and freight transport is primarily to fairly reflect the costs included in the price for using railway infrastructure. The factor of passenger/freight 
transport only makes it possible to reflect transport's negative effects in a general way (e.g., the degree of wear on the infrastructure, the use of transport line capacity, and limitations on the quality of services to other carriers).

\subsection{Combined transport}

The factor of combined transport should be maintained in the new price concept for railway infrastructure use. The reason for preserving it is that it is less costly for the infrastructure manager in comparison with other freight transport and does less to limit the quality of service for railway line use by other carriers if:

- trains show a high level of transport regularity and speed and

- there is relatively less wear on the infrastructure with respect to a smaller volume of train wagon repair.

\subsection{SHIPPING INDIVIDUAL WAGON LOADS}

The factor of individual, fully loaded wagons should be modified to more accurately reflect the areas where this type of transport is not sufficiently competitive from the RIA's perspective.

The current method of conferring timetable advantage in a blanket manner should be developed so that support for this area focuses on the sections of the first and last miles. Railway competitiveness is low for precisely these sections.

\subsection{TRACK CATEGORIZATION}

In the CR, railway tracks are divided into three categories: select nationwide tracks of European importance $-E$, other nationwide tracks $-C$, and regional tracks $-R$. This categorization has been enacted according to RIA track routing, the tracks' importance, and the scope of transport.

In the authors' opinion, this division does not take into account the actual quality of the tracks. The benefit of dividing the tracks into more categories is to take into account their actual quality from the perspective of maximum track speed. Moreover, for tracks with low track speed, this would lower the price for using the railway infrastructure, which could lead to a higher level of transport performance.

\subsection{INFRASTRUCTURE WEAR}

This specific key factor is used to allocate costs connected to infrastructure deterioration on individual trains in conjunction with European legislation.

The reason for implementing this specific factor is to take into account the different levels of wear on railway infrastructure by individual trains; so far, this has been employed using the component of price derived from gross ton kilometers. A reflection of railway infrastructure deterioration should be maintained in the price for using railway infrastructure.

\subsection{ETCS}

Equipping trains with the European Train Control System (ETCS) is key for ensuring that European railways are interoperable. Regulating this specific factor reflects the gradual growth in ETCS use and the overall carrier costs for supplemental train equipment.

Regulating this specific factor within tariff policy should derive from the condition that it have a neutral effect on infrastructure managers. Thus, the advantages for trains with ETCS and disadvantages for trains without ETCS should be balanced.

\subsection{EXPRESS TRAINS}

Priority is given to express trains in transit to the disadvantage of other types of trains. It is appropriate to reflect the difference in the quality of services for using the railway infrastructure for these trains by an additional fee on top of the basic price - primarily for passenger trains.

The reason for implementing this factor is to take into account the higher quality of services for express trains using railway infrastructure. They have priority over other trains, and their journey is therefore faster and has less interruptions - without the necessity of stopping and avoiding other trains.

\subsection{ThE TRACTION OF TRACTION UNITS}

This specific factor takes into account the cost to the public caused by transport. It is desirable to adequately regulate this factor in comparison with other modes of transportation and for it to simultaneously motivate carriers to lower the cost to the public.

Protecting the environment against the negative effects of transport is one of the EC's key strategic goals. However, the authors believe that measures taken in this area for railway transport are not distinctly restrictive in nature - conversely, they tend to support their use.

\subsection{Reducing NOISE LEVELS}

Taking into account the noise levels of trains and other means of transport requires composing comprehensive methods to make it possible to quantify the public costs caused by individual modes of transport. For this reason, it is appropriate to implement the factor of "reducing noise levels" once there is a unified and time-tested European method that is able to take into account roadway noise levels.

\subsection{The DEGREe OF TRACK UTILIZATION}

The general differentiation of peak and off-peak periods makes it possible to optimize the use of railway infrastructure capacity. The factor of utilization is appropriate only for certain tracks, and it must always be established on an individual basis.

Support for optimizing railway infrastructure utilization aims to decrease the overloading of individual 
routes primarily during peak hours as well as to increase the use of tracks that currently have a distinct reserve capacity.

International experience shows that it is not possible to influence certain effects of transport using universal tools; rather, it is necessary to react to them individually, e.g., by taking into account the operational peak and off-peak times for individual tracks.

\subsection{A TRAIN'S MINIMUM POWER DENSITY}

According to the authors, one specific factor that limits excessive consumption of railway infrastructure capacity is caused by insufficient traction unit performance and the consequently low speeds of certain trains. In turn, this lowers the risk of events occurring that block infrastructure capacity - caused by the gridlock of trains with insufficient traction units.

\section{Conclusion}

Charging for roadway and railway infrastructure is a sensitive topic, because any type of change has effects on financing infrastructure. When looking for an optimal solution for charging fees, it should ensure the equalization of transport between branches and a competitive transport system; it is also necessary to take into account the policy of both the $\mathrm{CR}$ and the EU.

Analysis of the factors listed above will be the basis for establishing a new method for calculating railway infrastructure prices. For a comprehensive evaluation, it is necessary to ascertain the relevant information and the Czech Ministry of Transport's projected approach, which is tied to fulfilling the goals of the Czech Republic's transportation policy and incorporating EU directives and regulations.

In comparing the CR's railway and roadway transport, where charges are levied for only $2.6 \%$ of the length of the roadway network and $98 \%$ of the railway network, it can be seen that there is obvious discrimination against railway transport in inter-branch competition. 